\title{
Early and late changes in sulphydryl group and copper protein concentrations and activities during drug treatment with aurothiomalate and auranofin
}

\author{
K J RAE ${ }^{1}$ C N N MACKAY,${ }^{1}$ C J McNEIL,${ }^{1}$ D H BROWN,${ }^{1}$ W E SMITH, ${ }^{1}$ \\ D LEWIS, ${ }^{2}$ AND H A CAPELL \\ From the ${ }^{l}$ Department of Pure and Applied Chemistry, University of Strathclyde, Glasgow; and the ${ }^{2}$ Centre for \\ Rheumatic Diseases, Baird Street, Glasgow
}

SUMMARY Superoxide dismutase activity (SOD), plasma and lysate thiol concentrations (PSH and $\mathrm{LSH}$ ), and caeruloplasmin oxidase activity (CP) reflect the underlying reduction-oxidation imbalance associated with rheumatoid arthritis (RA), and are believed to be involved in the protection of the cell against free radical activity. The early and late changes in these parameters have been observed and compared with standard clinical and biochemical assessments of disease activity in 90 patients with active RA, randomly assigned to receive either sodium aurothiomalate, auranofin, or auranofin placebo. An index based on clinical criteria was used to identify patients as responders or non-responders after 24 weeks of therapy. In the first six weeks of treatment a change in SOD activity and LSH concentration in a direction away from controls was followed by a return towards control levels in responders only. This suggests that in RA evidence of clinical improvement induced by gold drugs is preceded by an initial biochemical response in an inflammatory direction. The extracellular parameters PSH and CP did not show the same early response, but PSH levels in responders showed a slower change towards normal values, though at no time were values obtained that might suggest a complete remission. Thus the intracellular parameters appear to reflect an early effect of the drugs on cells which may possibly be of use in predicting the outcome of therapy, whereas the extracellular parameters provide confirmatory evidence for an eventual improvement.

Key words: rheumatoid arthritis, redox status, superoxide dismutase, caeruloplasmin.

The gold compound auranofin (1-thio- $\beta$-Dglucopyranosato) (triethylphosphine) gold 2, 3, 4, 6-tetra-acetate) (AF) is orally absorbed and appears to be effective in the treatment of rheumatoid arthritis. ${ }^{12}$ It is at present being comprehensively assessed in controlled clinical trials and compared with the injectable drug, sodium aurothiomalate (GST or Myocrisin); it produces a different profile of clinical and biochemical activities. ${ }^{3}$ Both GST and $\mathrm{AF}$ metabolise rapidly in vivo to produce a number of new gold compounds distributed in serum, cells, and most tissues. In the main, gold in vivo is complexed as gold(I) through the formation

Accepted for publication 21 April 1986.

Correspondence to Dr W E Smith, Department of Pure and Applied Chemistry, University of Strathclyde, Glasgow G1 1XL. of gold-sulphur bonds with accessible sulphydryl groups of proteins, peptides, and amino acids. ${ }^{34}$

In rheumatoid arthritis the plasma sulphydryl group concentration is low and the erythrocyte lysate sulphydryl group concentration high compared with those of normal controls. This indicates a change in the degree of oxidation of the fluids on each side of the cell membrane. ${ }^{5}$ The change in the reduction-oxidation (redox) status of the sulphydryl system is reinforced by the fact that the concentration of the main plasma oxidase, the copper containing protein caeruloplasmin, is raised in the disease state $^{67}$ and the activity of superoxide dismutase, an intracellular copper protein involved in the control of the concentration of superoxide ion $^{8}$ (a reduced form of oxygen), is decreased. ${ }^{910}$

The activities of the copper proteins and the 
sulphydryl group concentrations are believed to be linked. Caeruloplasmin is a specific oxidase for small molecules containing the sulphydryl group, such as cysteine and glutathione, producing the corresponding disulphides. ${ }^{11}$ By exchange with protein sulphydryl groups these disulphides are believed to influence plasma sulphydryl group concentrations. ${ }^{5} \mathrm{~A}$ close correlation between superoxide dismutase activity and glutathione concentration has also been shown in vivo and ex vivo using haemolysate. ${ }^{12}$

As part of the phagocytic process a burst of free radical activity is produced by the phagocytosing cell. Among other effects this activity causes the release of oxygen derived species such as superoxide ions, hydroxyl radicals, and hydrogen peroxide. ${ }^{13}$ Protection against these active oxygen species is afforded by glutathione ${ }^{14}$ and possibly caeruloplasmin $^{15}$ as well as superoxide dismutase. It has been suggested that the ability of patients with RA to metabolise these oxygen species is impaired and that the extent to which this occurs is related to the severity of the disease. Furthermore, SOD activity in polymorphonuclear leucocytes of children with juvenile rheumatoid arthritis is low ${ }^{9}$ and the levels in leucocytes of adults with rheumatoid arthritis is high. ${ }^{16}$

Thus both because of the possible chemical action of the gold drugs on sulphydryl group activities and because of the role of these groups and copper proteins in defining redox status and protecting the cell against free radical attack it seemed of value to study and compare the changes in the sulphydryl group concentration and copper enzyme activity caused by AF and GST.

\section{Patients and methods}

Ninety patients ( 28 male, 62 female) with classical or definite RA according to the criteria of the American Rheumatism Association were studied during 24 weeks of chrysotherapy. All patients were receiving optimal doses of non-steroidal antiinflammatory drugs (NSAIDs) and none were taking steroids or had previously been treated with gold in any form. In addition, none had received penicillamine, levamisole, or immunosuppressive drugs in the six months preceding the trial.

Initially, patients were randomly allocated to one of three treatment groups. Thirty patients (nine male, 21 female, median age 47 years, range 25-69 years, median duration of disease six years) were given an initial $10 \mathrm{mg}$ injection of GST followed by $50 \mathrm{mg}$ weekly until clinical response. Thereafter, the frequency of injection was reduced to fortnightly, three weekly, and, ultimately, four weekly. Thirty patients (eight male, 22 female, median age $55 \frac{5}{3}$ years, range 22-71 years, median duration of disease $\frac{\square}{\omega}$. 6.5 years) received auranofin tablets $(3 \mathrm{mg}$ twice? daily) throughout the study. Thirty patients $(11 \overrightarrow{\overrightarrow{\mathrm{N}}}$ male, 19 female, median age 55 years, range $31-72 \frac{\overrightarrow{0}}{0}$ years, median duration of disease 5.3 years) were $\frac{}{0}$ given placebo tablets identical with auranofin twice $\frac{\overline{\bar{m}}}{\overline{\frac{1}{2}}}$ daily.

Patients were initially monitored weekly, and assessments of disease activity were performed at ${ }^{\circ}$ weeks $0,3,6,12$, and 24 of treatment. The $\vec{\circ}$ parameters studied were: duration of morning stiff- $\overrightarrow{\vec{\omega}}$ ness recorded in minutes, pain score measured in centimetres on a $10 \mathrm{~cm}$ visual analogue scale, grip strength measured with an aneroid manometer? attached to a small cuff and inflated to $20 \mathrm{~mm}$ of mercury, Ritchie articular index, ${ }^{17}$ haemoglobin $\vec{\circ}$ concentration $(\mathrm{Hb})$, and Westergren erythrocyte ${ }_{\mathrm{C}}^{\infty}$ sedimentation rate (ESR).

Blood samples from 22 healthy volunteers (17윽 male, five female) were used to determine controlvalues for comparison with values found for the patient population. None were taking NSAIDs, $\overrightarrow{0}$ steroids, or had previously been treated with gold in any form.

The clinical indices of disease activity wege compared with laboratory measurements of tracellular redox status-namely, caeruloplasn oxidase activity and plasma thiol and intracellulär redox status in erythrocytes-namely, superoxide dismutase activity and lysate thiol concentrations. All examinations were made on fresh blood $\stackrel{\mathbb{Q}}{\circ}$ samples, all were separated within four hours of $\overrightarrow{\hat{O}^{\prime}}$ sampling, and all estimations were carried out at 3 standard times after separation and within 48 hours of sampling.

The methods of estimation have been describedo previously. ${ }^{510}$ Thiol concentrations in lysate and in 0 plasma were estimated by the method of Ellman ${ }^{18}$ O using the thiol-disulphide interchange reaction be-tween 5,5'-dithiobis(2-nitrobenzoic acid) and biolo-윽 gical thiols. Caeruloplasmin oxidase activity was measured by a modification of the method of 5 Menden et al $^{19}$ based on the caeruloplasmin cat- $\frac{D}{8}$ alysed oxidation of $p$-phenylenediamine to Bandrowski's base. Superoxide dismutase activity was N measured by the method of Misra and Fridovich ${ }^{20}$. based on the increase in the rate of photo-oxidation of $o$-dianisidine. The overall disease activity was $\omega$ assessed with the method of Mallya and Mace. ${ }^{21}$ This index defined four grades of disease activity fromo inactive (grade 1) to very active (grade 4) using a combination of morning stiffness, pain score, grip ${ }^{-}$ strength, articular index, $\mathrm{Hb}$ concentration, and $\frac{T}{\vec{O}}$ ESR. Clinical improvement was defined as a de- $\frac{\vec{D}}{\mathbb{D}}$ crease in activity grade by at least one grade after $24 \stackrel{?}{\frac{\pi}{8}}$ 
weeks of treatment. The significance of the difference between normal values and patient populations was calculated by the Mann-Whitney $U$ test and the difference between the treatment groups by the Kruskal-Wallis test. The significance of the change in all parameters at various stages of treatment was obtained with the Wilcoxon matched pairs signed rank test and the time dependent changes in SOD and LSH by a Spearman rank correlation. ${ }^{22}$

\section{Results}

The three treatment groups were similar in terms of age, duration of disease, sex ratio, and initial clinical and laboratory variables. The method of assessing disease activity as described by Mallya and Mace showed that the majority of patients (70/90) had

Table 1 Change in disease activity grade during the first 24 weeks of therapy with GST, AF, or placebo in patients with rheumatoid arthritis

\begin{tabular}{|c|c|c|c|c|c|c|c|}
\hline \multirow{3}{*}{$\begin{array}{l}\text { Treatment } \\
\text { group }\end{array}$} & \multicolumn{3}{|c|}{ Responders } & \multicolumn{4}{|c|}{ Non-responders } \\
\hline & \multirow{2}{*}{$\begin{array}{l}\text { Number } \\
\text { still on } \\
\text { therapy }\end{array}$} & \multicolumn{2}{|c|}{$\begin{array}{l}\text { Improved } \\
\text { one grade }\end{array}$} & \multicolumn{2}{|c|}{$\begin{array}{l}\text { Deteriorated } \\
\text { one grade }\end{array}$} & \multicolumn{2}{|c|}{ Unchanged } \\
\hline & & $n$ & $\%$ & $n$ & $\%$ & $n$ & $\%$ \\
\hline GST & 23 & 14 & 61 & 0 & 0 & 9 & 39 \\
\hline AF & 26 & 8 & 31 & 2 & 8 & 16 & 62 \\
\hline Placebo & 17 & 3 & 18 & 3 & 18 & 11 & 65 \\
\hline
\end{tabular}

moderately active disease, 14/90 had slightly active, and $6 / 90$ very active disease.

After 24 weeks of therapy $23 / 30$ patients (77\%) continued GST, 26/30 (87\%) continued AF, and $17 / 30(57 \%)$ continued placebo. Ten of the withdrawals from the placebo group were for persistent disease activity and lack of drug effect. Adverse effects or intercurrent illness accounted for all other patients who discontinued.

\section{CLINICAL ASSESSMENT}

Comparison of 0 to 24 week results (Wilcoxon) showed significant improvements in duration of morning stiffness, pain score, grip strength, Ritchie articular index, and ESR for both GST and AF groups. Patients who remained on placebo showed no significant improvement in any parameter. Table 1 shows the proportion of patients in each group who either improved or deteriorated by at least one grade of the activity index. When an improvement of one grade was used as a definition of change in disease activity there were 25 responders $(R)$ and 41 non-responders (NR) in the first six months of therapy.

\section{REDOX ASSESSMENT}

Redox parameters were all significantly different from normal at the start of the trial $(p<0.001$ Mann-Whitney). Table 2 shows the median and interquartile range of redox parameters for all

Table 2 Medians and interquartile (IQ) ranges of redox parameters for patients with rheumatoid arthritis and normal controls at the beginning of the trial

\begin{tabular}{|c|c|c|c|c|}
\hline & \multicolumn{2}{|l|}{ Extracellular } & \multicolumn{2}{|l|}{ Intracellular } \\
\hline & $C P(\mathrm{mg} / 100 \mathrm{ml})^{*}$ & PSH (umolll) & $S O D(\mu \mathrm{g} / \mathrm{ml})$ & LSH ( \\
\hline $\begin{array}{l}\text { Median } \\
\text { IQ range } \\
\text { Normal range }\end{array}$ & $\begin{array}{l}60 \cdot 1 \\
47 \cdot 0-74 \cdot 3 \\
38 \cdot 0-52 \cdot 8\end{array}$ & $\begin{array}{l}311 \\
266 \cdot 5-361 \\
457-543\end{array}$ & $\begin{array}{l}62 \cdot 0 \\
44 \cdot 0-85 \cdot 0 \\
78 \cdot 2-92 \cdot 5\end{array}$ & $\begin{array}{l}423 \\
264 \cdot 5-564 \cdot 5 \\
123-363\end{array}$ \\
\hline
\end{tabular}

*SI conversion: caeruloplasmin $\mathrm{mg} / 100 \mathrm{ml} \times 10=\mathrm{mg} / \mathrm{l}$.

Table 3 Medians $(M)$ and interquartile ranges (IQ) for the redox parameters during the first 24 weeks of therapy for each of the treatment groups*

\begin{tabular}{|c|c|c|c|c|c|c|}
\hline & \multicolumn{2}{|l|}{$G S T$} & \multicolumn{2}{|l|}{$A F$} & \multicolumn{2}{|l|}{ Placebo } \\
\hline & Week $0 \quad(n=29)$ & Week $24(n=21)$ & Week $0 \quad(n=29)$ & Week $24(n=25)$ & Week $0 \quad(n=29)$ & Week $24(n=17)$ \\
\hline \multirow[t]{2}{*}{$\mathrm{CP}$} & M $64 \cdot 0$ & $50 \cdot 5$ & $54 \cdot 8$ & $45 \cdot 1$ & $62 \cdot 1$ & $52 \cdot 2$ \\
\hline & IQ $51 \cdot 1-73 \cdot 8$ & $41 \cdot 9-67 \cdot 7$ & $46 \cdot 0-75 \cdot 0$ & $32 \cdot 3-64 \cdot 4$ & $48 \cdot 9-74.9$ & $38 \cdot 6-67 \cdot 4$ \\
\hline \multirow[t]{2}{*}{ PSH } & M 320 & 357 & 326 & 338 & 287 & 330 \\
\hline & IQ $272-362$ & $325-416$ & $269-372$ & $296-396$ & $250-349$ & $288-380$ \\
\hline \multirow[t]{2}{*}{ SOD } & M $50 \cdot 3$ & $71 \cdot 4$ & $66 \cdot 9$ & $67 \cdot 7$ & $66 \cdot 9$ & $74 \cdot 4$ \\
\hline & IQ $36 \cdot 7-69 \cdot 9$ & $43 \cdot 5-91 \cdot 1$ & $39 \cdot 7-85 \cdot 0$ & $51 \cdot 1-85 \cdot 0$ & $50 \cdot 3-92 \cdot 6$ & $63 \cdot 9-96 \cdot 3$ \\
\hline \multirow[t]{2}{*}{ LSH } & M 465 & 460 & 507 & 462 & 340 & 395 \\
\hline & IQ $339-638$ & $307-618$ & $257-584$ & $280-533$ & $232-442$ & $310-417$ \\
\hline
\end{tabular}

*Differences in numbers between Tables 1 and 2 and Table 3 are due to instrumental problems with one batch of samples. 
patients compared with those for normal controls. It can be seen that CP and LSH are raised and SOD and PSH are low. In addition, there were no significant differences in any of these parameters between the three treatment groups (KruskalWallis) and none which correlated with age, sex, or duration of disease.

Table 3 shows the changes in redox parameters between 0 and 24 weeks for the three treatments. The wide interquartile ranges in these groups mean that many apparent differences were not significant even at the $5 \%$ level, although if the direction of change in all groups was the same, a significant change could be observed if the groups were combined. CP activity decreased towards normal control values in all groups but did not reach significance at the $5 \%$ level in any. PSH rose towards normal control values in all groups, reaching significance in the GST and AF responder groups $(\mathrm{p}<0.02$ and $\mathrm{p}<0.025$ respectively). SOD activity also appeared to rise towards control levels in all groups but was significant only in the GST responder group $(p<0 \cdot 01)$. LSH rose away from normal control values in the placebo group $(p<0.02)$ and also in the GST responder and AF nonresponder groups; LSH fell in both the AF respon$\operatorname{der}(\mathrm{p}<0.01)$ and GST non-responder groups. With the exception of $\mathrm{LSH}$ all the changes were as expected from the analysis of complete treatment groups, with the largest changes being in the GST and AF improvers groups. The significant changes are listed in Table 4. Neither the GST nor AF non-responder groups showed any significant change and the only significant change in the placebo group was in the opposite sense, i.e. away from normal control values.

It was noted that the intracellular redox parameters (LSH and SOD) altered in the first few weeks of therapy, and consequently, all four parameters were examined graphically and the results for SOD and LSH are illustrated for the GST group (Figs 1a and 1b). The significance of these changes was examined (Wilcoxon) by comparing the results at each time point with those at week 0 (Table 5). The improvement in PSH at 12 and 24 weeks in the $\frac{}{\rho}$. responder group and the changes in SOD and LSH: are the most significant changes, together with an unexpected and unexplained observation of a signi- -0 ficant change in $\mathrm{CP}$ in the non-responder group at $\frac{\mathrm{C}}{\square}$ six weeks. As can be seen in Figs $1 \mathrm{a}$ and $1 \mathrm{~b}$ the $\frac{\bar{p}}{\bar{\alpha}}$ changes in SOD and LSH at about six weeks are in
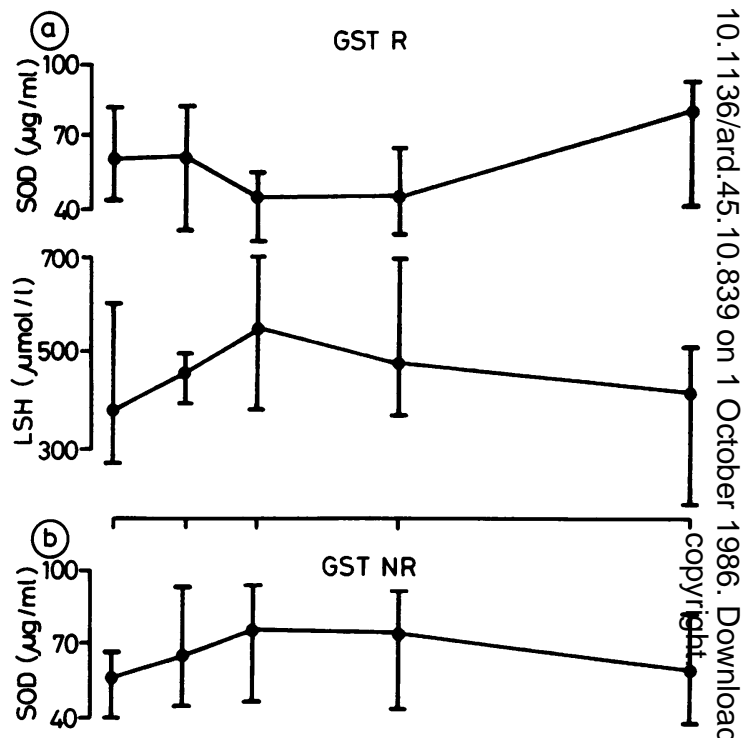

Fig. 1 Changes in redox parameters for GST (a) responders and (b) non-responders. The figure shows median and interquartile ranges at time points from zero to 24 weeks.

Table 4 Significant changes in redox parameters between 0 and 24 weeks. All changes are towards normal values unless marked*

\begin{tabular}{|c|c|c|c|c|c|c|}
\hline & \multicolumn{2}{|l|}{$G S T$} & \multicolumn{2}{|l|}{$A F$} & \multicolumn{2}{|l|}{ Placebo } \\
\hline & $R+(n=14)$ & $N R^{\dagger}(n=8)$ & $R(n=8)$ & $N R(n=17)$ & $R(n=4)$ & $N R(n=13)$ \\
\hline $\mathrm{CP}$ & - & - & $<0.10$ & - & - & \\
\hline PSH & $<0.02$ & - & $<0.025$ & - & - & \\
\hline SOD & $<0.01$ & - & - & - & - & \\
\hline LSH & - & - & $<0.01$ & - & - & $<0.02^{*}$ \\
\hline
\end{tabular}

$\dagger R=$ responder; $N R=$ non-responder. 
opposite senses for the responder and nonresponder groups, with the responders showing a change away from the control values. Similar changes in the auranofin group, though consistent with these findings, were not statistically significant, and no trend was observed in the placebo group, except that LSH rose continually.

We have previously shown a relation between SOD and LSH. This relation was found to be present at both 0 and 24 weeks (Table 6), but graphical presentation of the results indicated some change in slope, which suggested that both gold drugs did affect the nature of the correlation. The change in SOD $v$ the change in LSH was plc:ted (Fig. 2), and it was evident that a $\triangle \mathrm{SOD} v$ a $\triangle \mathrm{LSH}$ correlation was present in the placebo group $(p<0.005)$. This correlation, however, was not as clearly defined in the AF or GST groups.

\section{Discussion}

The criterion for inclusion of a patient in the trial was a clinical assessment of active disease and, as indicated by the large variation at the start of the trial, there was no attempt to preselect specific groups of patients on the basis of any individual parameter. The Mallya and Mace index proved a useful measure of the clinical efficacy of the drugs, which could then be used to assess the copper protein and sulphydryl group measurements. It

Table 5 Probability values from an analysis using a Wilcoxon test of the change in CP, PSH, SOD, and LSH between 0 and 3, 6, 12, and 24 weeks for responders and non-responders after treatment with GST

\begin{tabular}{|c|c|c|c|c|c|c|c|c|}
\hline \multirow[t]{2}{*}{ Week } & \multicolumn{4}{|c|}{ Responders $(n=14)$} & \multicolumn{4}{|c|}{ Non-responders $(n=9)$} \\
\hline & $C P$ & PSH & $S O D$ & $L S H$ & $C P$ & $P S H$ & $S O D$ & LSH \\
\hline $0-3$ & 0.3 & $0 \cdot 1$ & 0.8 & 0.5 & 0.4 & 0.2 & 0.2 & 0.7 \\
\hline $0-6$ & 0.7 & $0 \cdot 1$ & 0.04 & 0.08 & 0.05 & 0.6 & 0.06 & 0.04 \\
\hline $0-12$ & 0.6 & 0.06 & 0.7 & 0.3 & 0.8 & 0.4 & 0.5 & 0.4 \\
\hline $0-24$ & 0.5 & 0.03 & $0 \cdot 1$ & $0 \cdot 1$ & $0 \cdot 2$ & $0 \cdot 1$ & $0 \cdot 7$ & 0.9 \\
\hline
\end{tabular}

Table 6 Correlation between SOD and LSH for each of the three treatment groups

\begin{tabular}{|c|c|c|c|c|c|c|c|c|c|}
\hline \multirow[t]{2}{*}{ Week } & \multicolumn{3}{|c|}{$G S T$} & \multicolumn{3}{|c|}{$A F$} & \multicolumn{3}{|c|}{ Placebo } \\
\hline & $n$ & Corr & Sig & $n$ & Corr & Sig & $n$ & Corr & Sig \\
\hline 0 & 27 & -0.705 & 0.0005 & 26 & -0.762 & 0.0005 & 27 & -0.697 & 0.0005 \\
\hline 24 & 20 & -0.827 & 0.005 & 23 & -0.598 & 0.0025 & 17 & -0.758 & 0.0005 \\
\hline
\end{tabular}
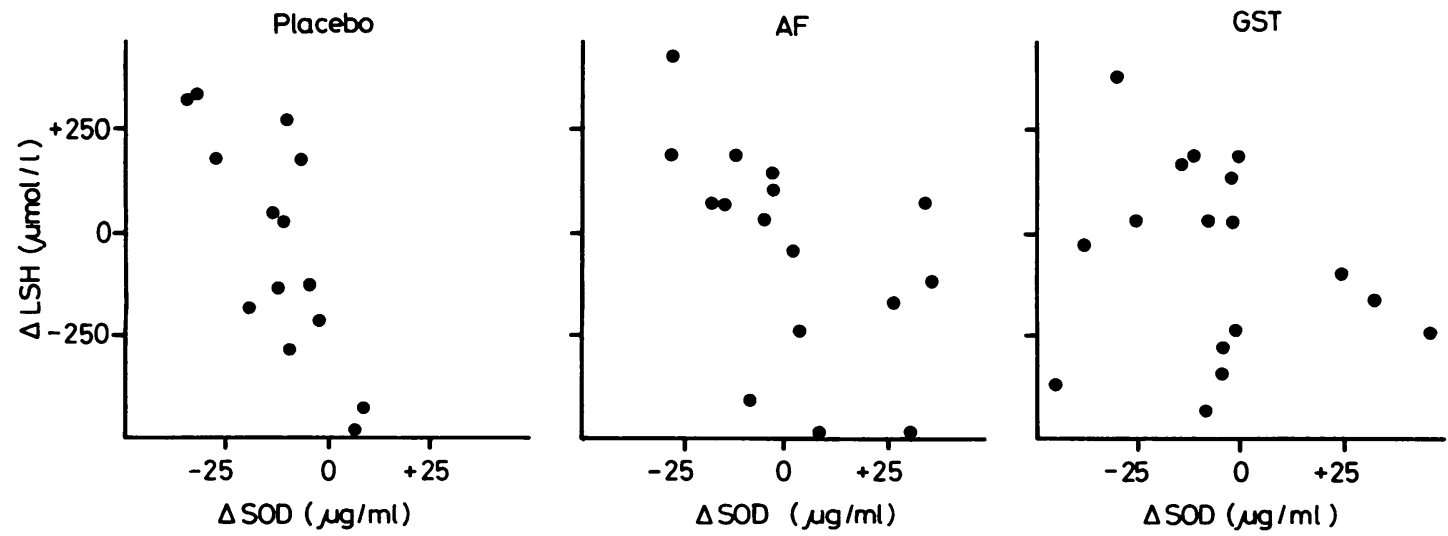

Fig. 2 Plot of the change in SOD against the change in LSH over 24 weeks. The gold drugs appear to affect the correlation between SOD and $\mathrm{LSH}$. 
should be stressed that the patients in the placebo treated group who remained on the therapy for six months are atypical of the group as a whole, as those with the most active disease had dropped out and are therefore not included in any statistical analysis of change with time. In addition, the high drop out rate of patients receiving placebo was largely because of worsening disease, and the tendency for some improvement to occur in the remaining placebo group is not unexpected. The deterioration in LSH even in this selected group, however, indicates that there is a difference in the biochemistry of this improvement compared with that produced by GST and AF. All patients in this study continued their regular daily intake of nonsteroidal anti-inflammatory drugs and as far as possible this was not varied during the trial, though it is possible that those who improved may have reduced the dosage. It is also possible that some non-responders are patients whom without treatment with GST or AF would have deteriorated rather than not improved. Both these points would reduce the significance of differences observed during therapy and may mean that the changes discussed are more conservatively estimated than should be the case. Neither possibility should produce any fake positive result. Furthermore, there was more flexibility in the GST regimen than with the new drug, in that at a later stage in therapy the dosage was where possible reduced. Since GST still shows the larger effects on the time scale studied the comparisons made remain valid, particularly since there is no accurate way of comparing dosage schedules between such different drugs.

Division of patients on each treatment into responders and non-responders allowed assessment of the biochemical parameters, not only longitudinally on the basis of the assigned treatment group but also on the basis of the response to treatment. In the three treatment groups the significant changes in GST and AF groups after 24 weeks were confined to the responder groups and were in a direction towards normal control values, whereas the only significant change in the placebo group was away from normal (Table 4). Despite clinical improvement in some patients, however, the inorganic biochemical parameters did not return to normal levels. This suggests that the effect of therapy on that aspect of the underlying biochemistry investigated is to create changes in the in vivo activity which produce a more quiescent state without returning the underlying biochemistry to a normal non-rheumatoid situation or producing a complete remission.

During the early weeks of therapy and before any clinical response could be discerned the intracellular parameters SOD and LSH showed a definite pattern of deterioration, particularly in the GST group, in $\frac{\mathrm{O}}{\mathrm{N}}$. those patients who later showed a clinical response. The pattern was most clearly seen when the GST $\overrightarrow{\vec{D}}$ group was subdivided into responders and non- $\bar{O}$ responders. No other clinical or biochemical parameters showed a clear pattern of early deterioration in the responder group. This result, if borne out in future studies, might mean that the likely response of a patient to a particular therapy could be predicted early in the course of therapy, even before the stage at which clinically assessed improvement becomes apparent.

Sulphydryl group concentrations on both sides of the cell membrane are higher than $C P$ and SOD (three groups per molecule of $\mathrm{CP}$ and $10^{3}$ groups per molecule of SOD respectively). Consequently, in an assessment of the action of these reactive materials it seems better to consider the sulphydryl groups first and to view the action of CP and SOD as they 음 affect the sulphydryl group-disulphide equilibrium. There has recently been increasing interest in the role of oxygen derived free radicals in inflammatory disease and tissue destruction, and a large amount of circumstantial evidence now exists which implicates these species in the pathogenesis of rheumatoig arthritis. One method of assessing the free radica activity is to monitor changes occurring in pars, meters relatively stable with time involved in the defence of the cell against free radical attack. Two such parameters are the intracellular compounds superoxide dismutase and glutathione. Both have $\underset{\perp}{ }$ been separately discussed and postulated as the $\overrightarrow{\bar{O}}$ prime defence mechanism, but there is no consensus as to their relative importance. In vitro there is no doubt that, molecule for molecule, SOD is more effective at removing superoxide ions than are thiols, but we have found that in the relative? concentrations of SOD and thiol found in either red or white cells it is the thiol concentration which is predominant. ${ }^{13}$ Furthermore, the superoxide ion is short lived, lasting approximately $10^{-5} \mathrm{~s}^{8}$ and thus will react close to the environment in which it is generated. This suggests that in many cases the $\rightarrow$ more ubiquitous sulphydryl system will be present at the reactive site in higher relative concentration N than that suggested above. In addition, the superoxide ion is only one of the free radicals believed to 0 be produced by the phagocytosing cell. For the $\omega$ others the specificity of SOD for superoxide ion would suggest that it would be less effective in these 0 cases, whereas the more general radical scavenging $\mathbb{D}$ activity of sulphydryl groups would indicate a role for them in these processes also.

The method of analysis used for thiol estimation does not detect haemoglobin thiol and consequently, $\frac{\rho}{\Phi}$ 
glutathione is the largest single component of LSH. As well as being a key element in the defence of the cell against attack by radicals in general, it is a key species in protein synthesis, a major source of non-protein bound sulphydryl groups within the cell, and, through the glutathione to diglutathione ratio, is used to control key enzyme processes in cellular metabolism. ${ }^{23}$ During inflammation cellular degradation of erythrocytes in the joint will release glutathione into the extracellular environment and hence into the plasma. The major individual component of the plasma sulphydryl group concentration (PSH) is the sulphydryl group on albumin. This group is protected from reaction with other proteins by being situated in a pocket in the protein structure. Exchange reactions between other proteins and small molecule disulphides are likely, however, and consequently an indirect equilibrium between each plasma protein and membrane sulphydryl groups is to be expected (Fig. 3). In this way sulphydryl reacting compounds, including small molecule disulphides ( $\left.\operatorname{RSSR}^{\prime}\right)$, can act to potentiate the various protein-SH concentrations in plasma. Caeruloplasmin is a specific oxidase for small molecule sulphydryl groups ( $\mathrm{RSH}$ ), producing small molecule disulphides (RSSR'). It would, therefore, be expected to have a direct effect on this equilibrium. Thus the effect of additional extracellular glutathione produced by inflammation would be to increase the concentration of plasma protein present in the disulphide form and cause a corresponding reduction in $\mathrm{PSH}$.

The inorganic biochemical parameters chosen are thus one measure of the oxidative status across the cell membrane and of the free radical protection system in erythrocytes. Since both erythrocytes and leucocytes are derived from the same stem cells, and since the mature erythrocyte can synthesise glutathione in much the same way as the leucocyte, it may be that the intracellular parameters-although determined in this study by erythrocyte

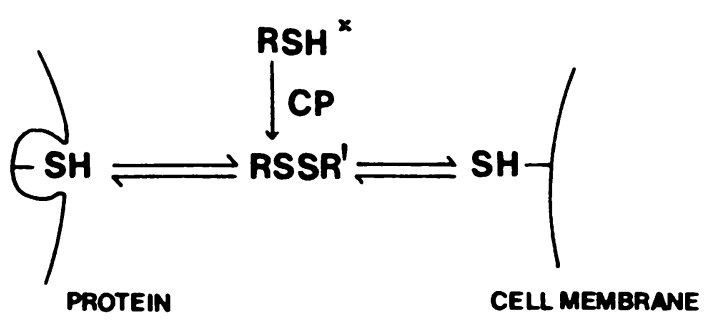

Fig. 3 Exchange reactions between plasma protein, small molecule disulphide, and cell membrane. $C P$ is caeruloplasmin, an oxidase with many postulated functions, one of which is the oxidation of the sulphydryl group in small molecules. concentration-also reflect analogous changes in leucocytes, though the exact nature of such changes seems to depend on the disease and cellular type.

One practical point arises from this worknamely, that sulphydryl groups interfere with most SOD assays in vitro, so that determination of SOD in lysates from red or white cells, for which the sulphydryl group concentration is not known, must be regarded as suspect. In the present study, however, the lysate sulphydryl group concentrations are low since the sulphydryl groups have been allowed to oxidise and consequently, with the exception of one or two of the highest results, are below the level at which added glutathione interferes with the assay. Thus the correlation between SOD activity and lysate thiol concentration appears to have a biochemical rather than an analytical meaning. In all cases at 0 and 24 weeks a significant correlation between SOD and LSH at the $0 \cdot 1 \%$ level is obtained (Table 6). When the change in SOD over the 24 week period is plotted against the change in the sulphydryl group concentration over the 24 week period, however, a very different pattern emerges (Fig. 2). The placebo group shows a significant correlation, but for auranofin this correlation is less obvious, and no correlation is evident for GST. Thus although the drugs over 24 weeks produce little change in mean concentration of lysate thiol or SOD, there is evidence that they do potentiate the free radical defence system in a rather more subtle way.

In conclusion, in agreement with previous studies $^{12} 2425$ this work has further confirmed that plasma thiol levels are an indicator, albeit a rather slow one, of eventual therapeutic outcome. The intracellular parameters give an early indication of therapeutic response analogous to that found for penicillamine. ${ }^{26}$ For penicillamine Munthe suggested that a rise of about $20 \%$ was required if the patient was to show response, and it is clear from our choice of responders that a similar rise is observed here (Fig. 1a). It is too soon to recommend this approach for use in clinical assessment but, taken together with other studies on the thiol system and bearing in mind the confirmatory value of two correlated analyses, it would seem to offer potential in this direction if confirmed in further studies. In any event the fundamental nature of the process and the nature of the relation between sulphydryl groups and superoxide dismutase activity would seem to be good subjects for further investigation.

D L is supported by a grant from Smith, Kline, and French. C J M is a Medical Research Council assistant. $K \mathrm{~J} R$ is supported by the International Copper Research Association. C N N M is supported by the Arthritis and Rheumatism Council. 


\section{References}

1 Finkelstein A E, Walz D T, Batista V, Mizraji M, Roisman F. Misher A. Auranofin: new oral gold compound for treatment of rheumatoid arthritis. Ann Rheum Dis 1976; 35: 251-7.

2 Berglof F E, Berglof K, Walz D T. Auranofin: an oral chrysotherapeutic agent for treatment of rheumatoid arthritis. $J$ Rheumatol 1978; 5: 68-74.

3 Proceedings therapeutic innovation in rheumatoid arthritis, worldwide auranofin symposium. J Rheumatol 1982; suppl. 8,9: 1-209.

4 Brown D H, Smith W E. The chemistry of the gold drugs used in the treatment of rheumatoid arthritis. Chem Soc Rev 1980; 9: 217-40.

5 Banford J C, Brown D H, Hazelton R A, McNeil C J, Smith W $E$, Sturrock $R$ D. Altered thiol status in patients with rheumatoid arthritis. Rheumatol Int 1982; 2: 107-11.

6 Scudder P R, Al-Timini D, McMurray W, White A G, Zoob B C, Dormandy T L. Serum copper and related variables in rheumatoid arthritis. Ann Rheum Dis 1978; 37: 67-70.

7 Brown D H, Buchan W W, El-Ghobary A, Smith W E, Teape J. Serum copper and its relationship to clinical symptoms in rheumatoid arthritis. Ann Rheum Dis 1979; 38: 174-6.

8 Johnston R B, Lehmeyer J E. The involvement of oxygen metabolites from phagocytic cells in bactericidal activity and inflammation. In: Michelson AM, McCord J M, Fridovich I, eds. Superoxide and superoxide dismutases. New York: Academic Press, 1977: 291-305.

9 Rister M, Bauermeister K, Gravert U, Gladtke E. Superoxide dismutase deficiency in rheumatoid arthritis. Lancet 1978; i: 1094.

10 Banford J C, Brown D H, Hazelton R A, McNeil C J, Sturrock R D, Smith W E. Serum copper and erythrocyte superoxide dismutase in rheumatoid arthritis. Ann Rheum Dis 1982; 41: 458-62.

11 Zgirski A F, Chidambaram V, Freiden E. Comparison of the catalytic activities of mammalian caeruloplasmin. In: Sorenson J $\mathrm{R} \mathrm{J}$, ed. Inflammatory diseases and copper. Clifton, $\mathrm{NJ}$ : Humana, 1982: 171-81.

12 McNeil C J, Banford J C, Brown D H, Smith W E. A relationship between thiols and the superoxide ion. FEBS Lett 1981; 133: 175-8.

13 Salin M L. McCord J M. Free radicals and inflammation: protection of the phagocytosing leukocytes by superoxide dismutase. J Clin Invest 1975; 59: 1319-23.

14 Fee J A. Is superoxide toxic? In: Bannister W H, Bannister J V, eds. Biological and clinical aspects of superoxide and superoxide dismutase. New York: Elsevier, 1980: 41-8.

15 Goldstein I M, Kaplan H B, Edelson H S, Weissman G. Caeruloplasmin, a scavenger of superoxide anion radicals. $J$ Biol Chem 1979; 254: 4040-5.

16 Youssef AR, Baron DN. Leucocyte superoxide dismutase in rheumatoid arthritis. Ann Rheum Dis 1983; 42: 558-62.

17 Ritchie D M, Boyle J A, McInnes J M, et al. Clinical studies $\vec{\circ}$ with an articular index for the assessment of joint tenderness in patients with rheumatoid arthritis. $Q J$ Med 1968; 37: 393-406.

18 Ellman G L. Tissue sulphydryl groups. Arch Biochem Biophys 1959; 82: 70-7

19 Menden E E, Boiano J M, Murthy L. Petering H G. ำ Modification of a $p$-phenylenediamine oxidase method to $\mathrm{cr}$ permit ceruloplasmin determinations. Anal Lett 1977; 10: $\overrightarrow{0}$ 197-204.

20 Misra H P, Fridovich I. Superoxide dismutase, a photochemical $\stackrel{\infty}{\omega}$ augmentation assay. Arch Biochem Biophys 1977; 181: 308-12.

21 Mallya R K, Mace B E W. The assessment of disease activity in 음 rheumatoid arthritis using a multivariate analysis. Rheumatol Rehabil 1981; 20: 14-6.

22 Siegel S. Non-parametric statistics: for the behavioural sciences. International student ed. Tokyo: McGraw-Hill, 1956.

23 Kosower N S. Kosower E M. The glutathione-glutathione disulphide system. In: Pryor W A, ed. Free radicals in biology. Vol. II. New York: Academic Press, 1976.

24 Pickup M E, Dixon J S, Bird H A. On the effects $\mathbb{E}_{\mathrm{f}} \infty$ anti-rheumatic drugs on protein sulphydryl reactivity in huma serum. J Pharm Pharmacol 1980; 32: 301-2.

25 Hall N D, Gillan A H. Effects of anti-rheumatic drugs protein SH reactivity of human serum. J Pharm Pharmacol 1979; 31: 676-80.

26 Munthe E, Kass E, Jellum E. D-Penicillamine induced increase in intracellular GSH correlated to clinical response in RA. $J \mathbb{\Phi}$ Rheumatol [Suppl] 1981; 7: 14-9. 